\title{
Endogenous business cycles and the dynamics of output, hours, and consumption
}

\author{
Stephanie Schmitt-Grohé* \\ Board of Governors of the Federal Reserve System
}

First draft: June 1997

This draft: March 1998

\begin{abstract}
This paper studies the business-cycle fluctuations predicted by a two-sector endogenousbusiness-cycle model with sector-specific external increasing returns to scale. It focuses on aspects of actual fluctuations that have been identified both as defining features of the business cycle and as ones that standard real-business-cycle models cannot explain: the autocorrelation function of output growth, the impulse response function of output to demand shocks, and the forecastable movements of output, hours, and consumption. For empirically realistic calibrations of the degree of sector-specific external returns to scale, the results suggest that endogenous fluctuations do not provide the dynamic element that is missing in existing real-business-cycle models.
\end{abstract}

Keywords: Business Cycles, Expectations-driven fluctuations

JEL Classification: E32

${ }^{*}$ I would especially like to thank Martín Uribe for many helpful discussions and suggestions. I would also like to thank seminar participants at Duke, Georgetown, Rutgers, the Federal Reserve Banks of Richmond and New York, and the Board of Governors for helpful comments. The opinions expressed in this paper are those of the author and do not necessarily reflect views of the Board of Governors of the Federal Reserve System or other members of its staff. Address for correspondence: Board of Governors of the Federal Reserve System, Washington DC 20551; sgrohe@frb.gov. 


\section{Introduction}

The hypothesis that actual business-cycle fluctuations are - at least in part-endogenous has a long history in economics. But only recently were endogenous-business-cycle models developed whose empirical validity can be evaluated using methods that have been standard in modern businesscycle research since the pioneering contribution of Kydland and Prescott (1982). In this class of endogenous-business-cycle models, the possibility of aggregate fluctuations typically arises as a consequence of increasing returns (e.g., Farmer and Guo, 1994) or variable markups of prices over marginal costs (e.g., Galí, 1994 and Schmitt-Grohé, 1997). However, these models have been criticized as empirically implausible because endogenous fluctuations arise only for increasing returns or markups that are significantly larger than available empirical estimates (Basu and Fernald, 1997; Schmitt-Grohé, 1997). This criticism lead to the development of models that display indeterminacy of the rational expectations equilibrium for substantially smaller returns to scale. An example is Benhabib and Farmer's (1996) model with sector-specific external returns to scale in the investment and consumption sectors. In this model the rational expectations equilibrium is indeterminate not

only for substantially smaller values of returns to scale than in previous models but also, and more importantly, for values of sector-specific returns to scale that are empirically realistic (Harrison, 1996).

As a result, the endogenous-business-cycle hypothesis can no longer be dismissed simply on the grounds that endogenous fluctuations occur only for unrealistic parameter specifications. Instead, its empirical relevance should be evaluated by comparing its predictions both to actual data and to predictions of alternative theories of the business cycle. The theoretical framework studied in this paper is a two-sector endogenous-business-cycle model with sector-specific external increasing returns to scale similar to the one developed by Benhabib and Farmer (1996). However, unlike in the Benhabib and Farmer model, where the production of both consumption and investment goods are subject to external returns to scale, increasing returns are limited to the production of investment goods since empirical studies have shown that the production of consumption goods exhibits constant returns to scale (Harrison, 1996).

The main question studied is whether the endogenous-business-cycle model can explain aspects of actual fluctuations that have been identified in the existing literature as ones that any convincing business-cycle model should be able to explain and that, at the same time, the standard real-business paradigm cannot explain. For example, Cogley and Nason (1995) demonstrate that standard real-business-cycle models cannot explain two stylized facts about U.S. GNP: positive serial correlation of GNP growth and a hump-shaped impulse response function to innovations in the temporary component. The endogenous-business-cycle model predicts that output growth is positively serially correlated and, indeed, much more so than a standard real-business-cycle model predicts. However, when the hypothesis that the endogenous-business-cycle model can account for the first eight autocorrelation coefficients of output growth is formally tested, it is rejected. This result is unchanged when a second source of uncertainty in the form of technology shocks is added. In the work of Cogley and Nason, the temporary component in actual GNP is identified using 
the method of Blanchard and Quah (1989) and is modeled in the theoretical economy as shocks to government spending. The fact that the model studied in this paper allows for equilibria with endogenous sources of uncertainty offers a novel interpretation of the innovations to the temporary component of GNP as sunspot shocks. The analysis suggests, however, that this identification is not successful in the sense that the theoretical model fails to predict the hump-shaped response to innovations in the temporary component so identified. Furthermore, the predicted impulse responses to innovations in the temporary and permanent component of GNP last much longer in the theoretical economy than in actual data. Rotemberg and Woodford (1996) highlight a further defining characteristic of actual business-cycle fluctuations that the real-business-cycle paradigm cannot explain. They demonstrate that real-business-cycle models (i) imply that output, hours, and consumption should not all be expected to move in the same direction whereas in the data forecastable changes in these three series are strongly positively correlated with each other and (ii) can explain only about 1 percent of the actual variance in forecastable movements in output. The results of this paper suggests that the endogenous-business-cycle model, like a real-business-cycle model, fails to predict the positive comovement among forecastable changes in output, hours, and consumption present in the data.

Finally, the model is modified to address the failure of the baseline model to predict procyclical consumption growth in the absence of intrinsic uncertainty. The baseline model predicts that output and consumption move in opposite directions in response to a sunspot shock because the labor demand schedule is downward sloping and fixed in the short run. Thus an increase in equilibrium hours in response to sunspot shocks is necessarily associated with a decline in the real wage. If consumption is a normal good, then consumption and hours and hence consumption and output will move in opposite directions. Rotemberg and Woodford (1992) show that the presence of countercyclical markups can imply that wages and output move in the same direction in response to demand shocks. Because a sunspot shock is similar to a demand shock (in the sense that it affects labor supply rather than labor demand) it has been conjectured that an endogenous-business-cycle model with countercyclical markups can predict procyclical consumption. Accordingly, the paper studies an extension of Galí's (1994) model that allows for sector-specific external returns to scale in the investment sector so that endogenous fluctuations arise for much smaller equilibrium markups than in Galí's original model. However, given empirically realistic values for the markup, this model, like the Benhabib and Farmer model, predicts countercyclical consumption growth in the absence of intrinsic uncertainty.

The remainder of the paper is organized as follows. Section 2 describes the model and its calibration. Section 3.1 presents the model's predictions about the volatility of hours, consumption, and investment growth relative to output growth, their first-order serial correlations, and the crosscorrelations between these variables and output growth. Section 3.2 investigates the autocorrelation function of output growth. Section 3.3 studies responses to permanent and temporary disturbances, and section 3.4 analyzes forecastable movements in output, hours, and consumption. Section 4 explores whether an endogenous-business-cycle model with countercyclical markups can account 
for the observed procyclicality of consumption growth, and section 5 concludes.

\section{The model}

The economy is assumed to be populated by a large number of identical infinitely lived households. The representative household chooses paths for consumption $\left\{C_{t}\right\}$ and total hours of work $\left\{H_{t}\right\}$ so as to maximize its lifetime utility,

$$
E_{0} \sum_{t=0}^{\infty} \beta^{t} u\left(C_{t}, H_{t}\right),
$$

subject to the following period-by-period budget constraint:

$$
C_{t}+S_{t} \leq w_{t} H_{t}+R_{t} S_{t-1}
$$

The period utility function $u($.$) is assumed to be concave, increasing in C_{t}$ and decreasing in $H_{t}$. $S_{t}$ denotes household savings in period $t, w_{t}$ denotes the wage rate in period $t$, and $R_{t}$ denotes the (stochastic) gross rate of return on savings held from period $t-1$ to period $t$. The household is also subject to some type of borrowing limit that prevents it from engaging in Ponzi-type schemes. The first order conditions associated with the household's optimization problem are

$$
\begin{aligned}
u_{c}\left(C_{t}, H_{t}\right) & =\lambda_{t}, \\
-u_{h}\left(C_{t}, H_{t}\right) & =\lambda_{t} w_{t}, \quad \text { and } \\
\lambda_{t} & =\beta E_{t} \lambda_{t+1} R_{t+1},
\end{aligned}
$$

where $\lambda_{t}$ is the marginal utility of wealth in period $t$. Solving (2) and (3) for $C_{t}$ and $H_{t}$ as functions of $\lambda_{t}$ and $w_{t}$ yields the following household demand and labor supply functions:

$$
\begin{aligned}
C_{t} & =C\left(\lambda_{t}, w_{t}\right), \quad \text { and } \\
H_{t} & =H\left(\lambda_{t}, w_{t}\right) .
\end{aligned}
$$

I will assume that preferences are compatible with balanced growth in consumption and wages and stationary hours. As shown in King, Plosser, and Rebelo (1988a), this assumption implies that there must exist a $\sigma>0$ such that (5) is homogeneous of degree one in $\left(w, \lambda^{-1 / \sigma}\right)$ and that $(6)$ is homogeneous of degree zero in $\left(w, \lambda^{-1 / \sigma}\right){ }^{1}$

The production side of the economy consists of two sectors. One sector produces consumption goods, and the other produces investment goods. Consumption is produced by competitive firms using the technology

$$
C_{t}=\left(K_{t}^{c}\right)^{\alpha^{c}}\left(z_{t} H_{t}^{c}\right)^{\left(1-\alpha^{c}\right)},
$$

\footnotetext{
${ }^{1}$ Rotemberg and Woodford (1992) show that these homogeneity assumptions further imply that $\epsilon_{h w}=\sigma \epsilon_{h \lambda}$, $\epsilon_{c w}=1+\sigma \epsilon_{c \lambda}$, and $\epsilon_{c w}=(\sigma-1) / \sigma s_{h} / s_{c} \epsilon_{h w}$, where $\epsilon_{i j}$ for $i=c, h$ and for $j=\lambda$, $w$ denotes the elasticity of $i$ with respect to $j$ in steady state.
} 
where $K_{t}^{c}$ denotes capital used in the production of consumption goods in period $t$, and $H_{t}^{c}$ denotes hours worked in the consumption sector in period $t$. The variable $z_{t}$ denotes the exogenous level of technology whose law of motion is given by

$$
\log z_{t}=\log \gamma_{z}+\log z_{t-1}+\sigma_{z} \epsilon_{t}^{z}
$$

where $\gamma_{z}>1, \sigma_{z}>0$, and $\left\{\epsilon_{t}^{z}\right\}$ is a mean-zero independently and identically distributed random variable with unit variance. Given the assumption of constant returns, perfect competition, and perfect mobility of labor and capital across sectors, the demands for factor inputs in the consumption sector are given by

$$
\begin{gathered}
w_{t}=\left(1-\alpha^{c}\right) C_{t} / H_{t}^{c} \text {, and } \\
u_{t}=\alpha^{c} C_{t} / K_{t}^{c}
\end{gathered}
$$

where $u_{t}$ is the rental rate of capital measured in units of consumption. Investment is produced by competitive firms using the technology

$$
I_{t}=A_{t}\left(K_{t}^{i}\right)^{\alpha^{i}}\left(z_{t} H_{t}^{i}\right)^{\left(1-\alpha^{i}\right)},
$$

where $K_{t}^{i}$ and $H_{t}^{i}$ are the capital and labor inputs in the investment sector in period $t$, and $A_{t}$ is an external factor that firms take as given when choosing their factor inputs. Letting $p_{t}$ denote the price of one unit of the investment good in units of the consumption good, the demand for capital and labor in the investment sector is

$$
\begin{aligned}
w_{t} & =\left(1-\alpha^{i}\right) p_{t} I_{t} / H_{t}^{i}, \quad \text { and } \\
u_{t} & =\alpha^{i} p_{t} I_{t} / K_{t}^{i} .
\end{aligned}
$$

The external factor is assumed to take the form

$$
A_{t}=\left(\bar{I}_{t} / z_{t}\right)^{\frac{\theta^{I}}{1+\theta^{I}}}
$$

where $\bar{I}_{t}$ is the aggregate level of output in the investment industry that each firm individually takes as given. In equilibrium, $I_{t}$ equals $\bar{I}_{t}$ so that the degree of external returns to scale in the investment sector is $\theta^{I}$. If $\theta^{I}=0$, then returns to scale in the investment sector are constant, and if, in addition, $\alpha^{i}=\alpha^{c}$, the model reduces to a standard one-sector real-business-cycle model like the one studied in King, Plosser, and Rebelo (1988b).

Market clearing in the labor market requires that total hours supplied are equal to labor demand

$$
H_{t}=H_{t}^{i}+H_{t}^{c}
$$

The aggregate capital stock, $K_{t}$, is equal to the sum of capital used in the investment sector and 
capital used in the consumption sector

$$
K_{t}=K_{t}^{i}+K_{t}^{c}
$$

It depreciates at the rate $\delta \in(0,1)$. The aggregate capital stock in period $t+1$ is equal to the undepreciated part of the current capital stock in period $t$ plus investment spending in period $t$,

$$
K_{t+1}=(1-\delta) K_{t}+I_{t}
$$

and thus is determined in period $t$. Capital is one of the assets available to households. The rate of return on investing in capital is equal to $\left[u_{t+1}+p_{t+1}(1-\delta)\right] / p_{t}$. Using this expression to replace $R_{t+1}$ in (4) yields

$$
\lambda_{t}=\beta E_{t} \lambda_{t+1} \frac{u_{t+1}+p_{t+1}(1-\delta)}{p_{t}} .
$$

An equilibrium is a set of sequences $\left\{C_{t}, H_{t}, w_{t}, u_{t}, p_{t}, H_{t}^{i}, K_{t}^{i}, H_{t}^{c}, K_{t}^{c}, K_{t}, I_{t}, \lambda_{t}, A_{t}\right\}$ satisfying (2)-(3), (7), (9)-(18), and a no-Ponzi condition given $K_{0}$ and the exogenous process $\left\{z_{t}\right\}$ described in equation 8. I restrict the analysis to small fluctuations around a steady-state growth path and approximate a stationary equilibrium involving small fluctuations around a steady state growth path by the solution to a log-linear approximation to the equilibrium conditions as in King, Plosser, and Rebelo (1988a). The coefficients involved in this log-linear approximation can be related to factor shares and factor elasticities of the model observed along the steady-state growth path.

\subsection{Calibration}

The main reason for considering the particular endogenous-business-cycle model described above is that expectations-driven fluctuations arise for empirically realistic calibrations of the degree of returns to scale. Benhabib and Farmer (1996) demonstrate that in this model the rational expectations equilibrium is indeterminate when external returns to scale in both the investment and the consumption sectors are positive. Building on the work of Benhabib and Farmer, Harrison (1996) shows that indeterminacy occurs even if returns to scale are constant in the consumption sector as long as returns to scale in the investment sector are large enough. ${ }^{2}$ To calibrate the degree of external returns to scale in the investment sector, I draw on the empirical estimates presented in Harrison (1996). She constructs estimates of the size of returns to scale in the consumption and investment sectors individually using 2-digit and 4-digit U.S. manufacturing data. For the investment sector, Harrison finds that the null hypothesis of constant internal and positive external returns to scale cannot be rejected. Her point estimates of external returns to scale in the investment

\footnotetext{
${ }^{2}$ The same insight can be found in Perli (1995). Perli considers a two-sector model with external increasing returns to scale in the sector that produces the investment good and constant returns to scale in the other sector that produces consumption goods. He demonstrates that the rational expectations equilibrium is indeterminate for sufficiently large returns to scale in the investment sector. Contrary to Benhabib and Farmer's or Harrison's model, Perli's model allows for the possibility that the investment good can also be used for consumption (this assumption is, however, inessential for the indeterminacy result).
} 
sector lie between .060 and .067 , depending on whether the 2-digit or the 4-digit data set is used and depending on the set of instruments in the regressions. ${ }^{3}$

The other parameters that need to be calibrated can be found in most quantitative businesscycle studies, and I follow that literature by assuming that the drift in the technology process, $\gamma_{z}$, is equal to 1.6 percent per year; the intertemporal elasticity of substitution, $\sigma$, is equal to 1 ; the real interest rate, $r$, is 4 percent per year; and the depreciation rate, $\delta$, is 10 percent per year. The remaining three parameters to be calibrated are the labor share in the consumption and the investment sectors, $1-\alpha^{c}$ and $1-\alpha^{i}$, respectively, and the elasticity of labor supply, $\epsilon_{h w}$. The minimum degree of external returns to scale for which the equilibrium is indeterminate is a function of all parameters of the model but is most sensitive to the values of the labor shares and the labor supply elasticity. Specifically, the higher the labor shares and the labor supply elasticity, the smaller is the minimum degree of returns to scale that renders the equilibrium indeterminate. To ensure that the equilibrium is indeterminate for values for the investment externality, $\theta^{I}$, that lie within a 95 percent confidence interval around that point estimate, I assume that labor is indivisible as in Hansen (1985) - that is, $\epsilon_{h w}=\infty$,- and that both labor shares are equal to 70 percent. For this calibration of the model, the rational expectations equilibrium is locally indeterminate for $\theta^{I}>$.091. The highest degree of external returns to scale that lies within the respective 95 percent confidence intervals around Harrison's point estimates for $\theta^{I}$ is .1 , and thus I assign this value to the investment-specific externality.

\section{Comparing predicted with observed fluctuations}

To evaluate the ability of the endogenous-business-cycle model developed in section 2 to explain the character of aggregate fluctuations observed in the U.S. economy, I compare its predictions about four aspects of the business cycle to the data. First, I ask whether the model can explain simple measures of comovements in output, consumption, investment, and hours growth. Second, I analyze whether the model can account for the observed characteristics of the autocorrelation function of output growth. Third, I compare the responses of output and hours to permanent and temporary disturbances predicted by the model with those estimated from U.S. data, and finally I investigate whether the model can capture the comovements of forecastable changes in output, hours, and consumption.

\footnotetext{
${ }^{3}$ Basu and Fernald (1995) argue that there are no significant external effects in 2-digit U.S. manufacturing industry data. Harrison uses the same data source as Basu and Fernald but arrives at a different conclusion. One difference between the two studies is that in Harrison industries belonging to the investment sector need not have the same size externality as industries belonging to the consumption sector, whereas in Basu and Fernald the degree of externality is constrained to be the same across all industries considered. Burnside (1996) estimates returns to scale for each 2-digit manufacturing industry individually using the same data as Basu and Fernald. He also argues that there are no significant external returns to scale in 2-digit U.S. manufacturing data. However, like Basu and Fernald, he does not allow for sector-specific externalities.
} 


\subsection{Simple measures of comovement}

The standard tool to evaluate the empirical success of a particular business-cycle model is to compare the predictions a calibrated version of the model makes about a small set of unconditional second moments with their empirical counterparts. This methodology has been applied in the real as well as in the endogenous-business-cycle literature. For example, Benhabib and Farmer (1996) analyze a version of the model presented in section 2 driven by transitory, though persistent, shocks to the level of technology and by sunspot shocks that are perfectly correlated with the innovations to the level of technology. They conclude that, while the model-implied population moments do not exactly match the data, they are not implausibly different either. In a one-sector framework, Farmer and Guo (1994) show that an endogenous-business-cycle model driven solely by revisions in expectations predicts comovements of macroeconomic aggregates at business-cycle frequencies that are not clearly less consistent with the data than are those implied by the standard technology-shockdriven, real-business-cycle model. Similarly, Galí (1994) and Schmitt-Grohé (1997) have shown that one-sector endogenous-business-cycle models imply simple measures of aggregate comovements broadly consistent with those observed. However, the one-sector endogenous-business-cycle models just cited have been criticized on the grounds that the rational expectations equilibrium in these models is (locally) indeterminate only for unrealistically high returns to scale.

I begin by assuming that there are no shocks to economic fundamentals and that recurring fluctuations in aggregate activity arise solely as a consequence of revisions in agents' expectations about the future path of the economy. I will refer to such an account of business-cycle fluctuations as the endogenous-business-cycle hypothesis. It shares with the baseline real-business-cycle model the implicit assumption that a single source of uncertainty is capable of accounting for the majority of fluctuations. In real-business-cycle theory, this single disturbance takes the form of an innovation to total factor productivity, whereas in the endogenous-business-cycle theory it reflects innovations in people's expectations about the future path of the economy.

Table 1 presents the standard deviation of consumption, hours, and investment growth relative to the standard deviation of output growth. The first row shows estimates from quarterly postwar

Table 1: Estimated and Predicted Standard Deviation Relative to Output Growth

\begin{tabular}{lccc}
\hline \hline & $\Delta c_{t}$ & $\Delta h_{t}$ & $\Delta i_{t}$ \\
\hline U.S. data & 0.52 & 0.94 & 2.54 \\
EBC model & 0.47 & 1.45 & 5.39 \\
RBC model & 0.53 & 0.49 & 2.47 \\
\hline Note. $\Delta x_{t}$ denotes the change in \\
the logarithm of $X$ from $t-1$ to $t$.
\end{tabular}

U.S. data, ${ }^{4}$ the second row shows the relative standard deviations implied by the endogenousbusiness-cycle model, and the third row shows, for comparison, the predictions of a real-business-

\footnotetext{
${ }^{4}$ The estimates for consumption and investment growth are taken from table 1 of King, Plosser, and Rebelo (1988b). The statistics of hours are based on the hours time series described in section 3.3.
} 
cycle model. The predictions of the real-business-cycle model are computed using the same calibration used for the endogenous-business-model but for the externality in the investment sector which is set to zero $\left(\theta^{I}=0\right)$ and the growth rate of technology which is assumed to be stochastic $\left(\sigma_{z}>0\right)$. In that case, the model collapses to the one-sector real-business-cycle model studied in King, Plosser, and Rebelo (1988b). The relative volatility of consumption growth predicted by both the endogenous and the real-business-cycle model is close to the one observed. However, the relative volatilities of investment and hours growth predicted by the endogenous-business-cycle model are much larger than those observed. By contrast, the relative volatilities of investment and hours growth predicted by the real-business-cycle model are slightly smaller than the corresponding observed relative volatilities.

Table 2 presents the first order autocorrelation of consumption, hours, and investment growth. ${ }^{5}$ As is well known, the real-business-cycle model does not predict positive serial correlation in con-

Table 2: Estimated and Predicted First-Order Autocorrelation

\begin{tabular}{lccc}
\hline \hline & $\Delta c_{t}$ & $\Delta h_{t}$ & $\Delta i_{t}$ \\
\hline U.S. data & 0.16 & 0.64 & 0.48 \\
EBC model & 0.19 & 0.16 & 0.16 \\
RBC model & 0.08 & -0.04 & -0.03 \\
\hline Note. $\Delta x_{t}$ denotes the change in \\
the logarithm of $X$ from $t-1$ to $t$.
\end{tabular}

sumption, hours, and investment growth (see King, Plosser, and Rebelo 1988b), whereas in U.S. postwar data these autocorrelations are positive and significantly different from zero. This discrepancy between the data and the predictions of the real-business-cycle model is one of the reasons that it is sometimes argued that the real-business-cycle model lacks an endogenous propagation mechanism. Table 2 reveals that the endogenous-business-cycle model can predict some positive serial correlation in growth rates of the private components of aggregate demand and of aggregate hours but not so much as is present in the data.

Table 3 presents the cross-correlation of output growth with consumption, hours, and investment growth. In the data, consumption, investment, and hours growth are positively correlated

Table 3: Estimated and Predicted Cross-Correlation between $\Delta y_{t}$ and $\Delta c_{t+j}, \Delta h_{t+j}$, and $\Delta i_{t+j}$

\begin{tabular}{|c|c|c|c|c|c|c|c|c|c|}
\hline & \multicolumn{3}{|c|}{$\Delta c_{t+j}$} & \multicolumn{3}{|c|}{$\Delta h_{t+j}$} & \multicolumn{3}{|c|}{$\overline{\Delta i_{t+j}}$} \\
\hline & $j=1$ & $j=0$ & $j=-1$ & $j=1$ & $j=0$ & $j=-1$ & $j=1$ & $j=0$ & $j=-1$ \\
\hline U.S. data & 0.26 & 0.45 & 0.42 & 0.61 & 0.77 & 0.38 & 0.36 & 0.61 & 0.40 \\
\hline EBC model & -0.04 & -0.95 & -0.23 & 0.13 & 0.99 & 0.19 & 0.14 & 0.99 & 0.19 \\
\hline RBC model & 0.06 & 0.99 & -0.01 & -0.07 & 0.98 & 0.00 & -0.04 & 0.99 & 0.00 \\
\hline
\end{tabular}

Note. $\Delta x_{t+j}$ denotes the change in the logarithm of $X$ from $t+j-1$ to $t+j$.

with lagged, future, and contemporaneous output growth. The endogenous-business-cycle model

\footnotetext{
${ }^{5}$ The predictions of the model for the autocorrelation of output growth will be discussed in section 3.2.
} 
can capture the positive cross-correlation between output growth and both investment and hours growth, but it fails to predict the positive cross-correlation between consumption and output growth. The real-business-cycle model predicts a contemporaneous correlation of consumption, investment, and hours with output growth of close to one, which is too high; and for lags of either +1 or -1 quarters, it predicts a cross-correlation between output growth and consumption, investment, or hours growth of zero, which is too low.

In summary, there are two major discrepancies between actual comovements in growth rates of macroeconomic aggregates and those predicted by the endogenous-business-cycle model: (1) the volatility of investment and hours growth relative to output growth is excessive, and (2) the predicted pattern of cross-correlation between consumption and output growth has the wrong sign.

The failure of the endogenous-business-cycle model to account for the observed cross-correlation between consumption and output growth stems from the fact that the model predicts a near perfect negative correlation between wages and output. The model implies an aggregate labor demand curve that is decreasing in the wage rate. ${ }^{6}$ Ignoring for the moment movements in the aggregate capital stock, the model implies that any increase in aggregate hours (and thus output) is associated with a decrease in the wage rate since the economy is restricted to moving along the downwardsloping labor demand curve. ${ }^{7}$ In equilibrium, movements along the downward-sloping labor demand curve have to be associated with shifts in the labor supply curve. Provided consumption and leisure are normal goods, consumption and wages will move along such an equilibrium path in the same direction. And the negative correlation between wages and output thus implies a negative correlation between consumption and output.

Suppose that, in response to an extrinsic shock, consumption is higher than it was expected to be last period. From our assumptions about preferences it follows that the increase in consumption must be associated with an increase in wages. Because the aggregate capital stock is predetermined, the aggregate labor demand curve is unchanged, and an increase in wages must be associated with a decline in aggregate hours. Therefore, current output has to be lower than expected implying a conditional correlation between output and consumption growth that is negative. The overall correlation between the level or the growth rate of consumption and the respective measure of output might still be positive because of the positive overall correlation between capital and output. ${ }^{8}$ These arguments suggest that for the endogenous-business-cycle model studied here to predict procyclical consumption growth, some source of fundamental uncertainty must be added to the model.

\footnotetext{
${ }^{6}$ To see this, note that, since $\alpha^{c}=\alpha^{i}$, the capital-labor ratio is the same in both sectors. The labor demand schedule in the consumption sector is given by $H_{t}^{c}=\left(\frac{(1-\alpha) z_{t}^{1-\alpha}}{w_{t}}\right)^{(1 / \alpha)} K_{t}^{c}$. Therefore, $H_{t}=H_{t}^{c}+H_{t}^{i}=\left(\frac{(1-\alpha) z_{t}^{1-\alpha}}{w_{t}}\right)^{(1 / \alpha)} K_{t}$.

${ }^{7}$ Christiano and Eichenbaum (1992) argue that the single most salient shortcoming of one-shock real-businesscycle models is that they cannot predict the "Dunlop-Tarshis observation" - the observed near-zero correlation between labor productivity and aggregate hours. The endogenous-business-cycle model also fails to correctly predict the Dunlop-Tarshis observation. Contrary to the real-business-cycle model, which predicts a near-perfect positive correlation (.94), the endogenous-business-cycle model fails because it predicts a near-perfect negative correlation $(-.98)$.

${ }^{8}$ For example, Benhabib and Farmer (1996) report an overall correlation between the level of output and the level of consumption in the endogenous-business-cycle model of 0.32 . Their calibration differs from the one I use in that it assumes a lower labor share of .65 , no growth, and an externality of .2 in the investment and consumption sectors. However, for this calibration, the overall correlation between output and consumption growth is still negative at -.59 .
} 
Specifically, I introduce intrinsic uncertainty by assuming that the logarithm of the level of technology follows a random walk with drift, as described in (8). This assumption implies that a positive technology shock has a permanent effect on the level of output and is motivated by the fact that, as many authors have shown, U.S. output can be characterized as a unit-root process. The purpose of the extension is twofold. First, the introduction of a technology shock enables the model to predict procyclical wages and, hence, procyclical consumption. The second purpose is to document that, when augmenting the real-business-cycle model with belief shocks or alternatively augmenting the endogenous-business-cycle model with technology shocks, there exist assumptions for the joint stochastic process for the sunspot and the technology shock such that the predictions of both models are improved.

To complete the calibration of the model, the coordination mechanism to revise expectations must be specified. This mechanism is described by the covariance matrix between technology and sunspot shocks. The covariance matrix has three free parameters: the variance of the sunspot or belief innovation, $\sigma_{b}^{2}$; the variance of the technology growth innovation, $\sigma_{z}^{2}$; and the correlation between the sunspot and the technology shock, $\rho_{b z}$. Because the approximate model solution is linear, the comovements analyzed in tables 1-3 depend only on the ratio $\frac{\sigma_{b}^{2}}{\sigma_{z}^{2}}$ and the correlation between the technology and sunspot shocks, $\rho_{b z}$. I calibrate these two free parameters so as to match the relative volatility of consumption and hours growth. The result of this calibration strategy is to set the variance of the sunspot shock one fifth that of the technology shock and to set the correlation between the sunspot and the technology shock to -.965. Table 4 presents the results. As expected,

Table 4: Predicted Comovements when the Model is Subject to Technology and Belief Disturbances

\begin{tabular}{lccc}
\hline \hline & $\Delta c_{t}$ & $\Delta h_{t}$ & $\Delta i_{t}$ \\
\hline Std. dev. relative to $\Delta y_{t}$ & 0.52 & 0.94 & 3.74 \\
Autocorrelation & 0.15 & 0.77 & 0.72 \\
Cross-correlation with & & & \\
$\Delta y_{t-1}$ & -0.27 & 0.65 & 0.62 \\
$\Delta y_{t}$ & 0.37 & 0.86 & 0.92 \\
$\Delta y_{t+1}$ & -0.06 & 0.53 & 0.53 \\
\hline
\end{tabular}

adding a technology shock generates procyclical consumption growth in the model. ${ }^{9}$ The predicted cross-correlations between consumption growth and lagged or leading output growth are still of the wrong sign. Overall, the results suggest that, at least with respect to the fifteen moments considered here, the endogenous-business-cycle model augmented with technology shocks is more consistent with the data. In addition, it is more consistent with the data than a standard real-business-cycle model, since it can account for positive serial correlation, positive cross-correlation at lags of +1 or 1 quarters (with the exception of consumption), and positive but less-than-perfect contemporaneous comovements in growth rates of consumption, hours, and investment (which are the three main

\footnotetext{
${ }^{9}$ Other authors have analyzed the comovement of consumption and output in an endogenous-business-cycle model driven by sunspot and technology shocks. For example, Weder (1997) shows that the level of Hodrick-Prescott detrended consumption is positively correlated with the level of detrended output.
} 
problems of the real-business-cycle model) without doing worse along the other dimensions. ${ }^{10}$ In this context it is interesting to note that adding an additional source of fundamental uncertainty to the real-business-cycle model does not seem to eliminate the three principal shortcomings of the real-business-cycle model mentioned above. For example, adding a demand shock in the form of stochastic government purchases does not necessarily bring predicted and actual measures of comovements closer together (see appendix A, tables A1 and A2).

\subsection{The autocorrelation function of output growth}

One of the central weaknesses of the real-business-cycle paradigm as a convincing explanation of business-cycle fluctuations is its failure to predict positive serial correlation in output growth rates. In U.S. postwar data, real output growth rates are positively serially correlated, and the serial correlation is significantly greater than zero for lags of one and two quarters (Cogley and Nason, 1995). This discrepancy between actual and theoretical autocorrelation functions was first pointed out by King, Plosser, and Rebelo (1988b) in a real-business-cycle model driven solely by permanent technology shocks. In particular, their calibrated model predicts that the first and second order serial correlations of output growth are equal to .02, whereas the estimated first and second order serial correlations of output growth are .37 and .22 , respectively.

Cogley and Nason (1995) show that this discrepancy between actual and theoretical autocorrelation functions is present in a wide class of real-business-cycle models. Specifically, they show that the predicted autocorrelation function of output growth remains close to zero in extensions of the standard real-business-cycle model that allow for government purchases shocks, home production, gestation lags, or capital adjustment costs. ${ }^{11}$

In what follows, I argue that the endogenous-business-cycle model predicts serial correlation in output growth that is albeit larger and therefore closer to the data but not sufficiently so to be consistent with the data. Figure 1 shows with a solid line the estimated autocorrelation function of real per capita output growth using quarterly U.S. data from the second quarter of 1948 to the second quarter of $1997 .^{12}$ The dashed lines describe a two-standard-error confidence band around the estimated autocorrelation function. Output growth is positively correlated over short horizons and has weak, possibly insignificant, negative autocorrelation over long horizons. The point estimate of the first-order autocorrelation is .37 with a confidence interval of $(.23, .51)$ and the second-order

\footnotetext{
${ }^{10}$ The model further predicts that $\operatorname{corr}\left[\Delta\left(y_{t}-h_{t}\right), \Delta h_{t}\right]=-.16$, which is more consistent with the Dunlop-Tarshis observation than the correlation predicted by the model without intrinsic uncertainty. In my data set, the correlation between $\Delta h_{t}$ and $\Delta\left(y_{t}-h_{t}\right)$ is equal to -.27 .

${ }^{11}$ There are, however, some variations of the real-business-cycle paradigm that correctly predict the positive serial correlation observed. For example, in the presence of employment lags (as in Burnside, Eichenbaum, and Rebelo, 1993) or adjustment costs in capital and labor, the predicted first-order serial correlation in output growth is consistent with the data. Other modifications of the real-business-cycle that pass the autocorrelation test assume serially correlated technology growth or government purchases that follow an $\mathrm{AR}(2)$ process. However, both of these modifications rely on assumptions about the exogenous driving processes that are counterfactual.

${ }^{12}$ Output is measured as GNP in chain-weighted 1992 dollars. This series comes from the Department of Commerce's Survey of Current Business (table 1.10). The output series is seasonally adjusted. Population is measured as the civilian, noninstitutional population aged 16 or older. This series comes from the Bureau of Labor Statistics' Employment Situation Release.
} 
autocorrelation is .22 with a confidence interval of $(.06, .38)$. The autocorrelation function of output growth predicted by the endogenous-business-cycle model is shown with a crossed line. The endogenous-business-cycle model predicts serial correlation of .18 for lags of one quarter and of .12 for lags of two quarters. The predicted first-order serial correlation lies just below the lower bound of the confidence band around the estimated autocorrelation function, and the predicted secondorder serial correlation lies well within the band. For comparison, the autocorrelation function of output growth implied by a real-business-cycle model in which technology shocks are the only source of uncertainty (the dotted line) is also shown. As discussed earlier, the real-business-cycle model predicts no autocorrelation in output growth rates.

Next, I address two robustness questions. First, the estimate of the empirical autocorrelation function is subject to sampling error while the autocorrelation function reported for the theoretical models is the population autocorrelation function. One can introduce sampling error into the model autocorrelation function by computing it from simulated time series data. In this way one can formally test the hypothesis that the difference between the estimated and the simulated autocorrelation functions can be accounted for by the sampling error in the simulated time series of output growth. ${ }^{13}$ Second, I investigate how the autocorrelation function predicted by the model changes when a technology shock is added.

Specifically, I test whether the first eight autocorrelation coefficients match the data using the following generalized Wald statistic:

$$
Q_{a c f}=(\hat{\mathbf{c}}-\mathbf{c})^{\prime} \hat{\mathbf{V}}_{\mathbf{c}}^{-1}(\hat{\mathbf{c}}-\mathbf{c})
$$

where the vector $\hat{\mathbf{c}}$ denotes the first eight elements of the estimated autocorrelation function of output growth, and the vector $\mathbf{c}$ denotes the first eight elements of the mean of $N(=1000)$ simulated autocorrelation functions from the model economy. That is,

$$
\mathbf{c}=\frac{1}{N} \sum_{i=1}^{N} \mathbf{c}_{\mathbf{i}},
$$

where $\mathbf{c}_{\mathbf{i}}$, the model-implied autocorrelation function, is computed from a simulated time series of the same length as the actual time series, namely 197 quarters. $\hat{\mathbf{V}}_{\mathbf{c}}$ is the covariance matrix of the simulated autocorrelation coefficients

$$
\hat{\mathbf{V}}_{\mathbf{c}}=\frac{1}{N} \sum_{i=1}^{N}\left[\mathbf{c}_{\mathbf{i}}-\mathbf{c}\right]\left[\mathbf{c}_{\mathbf{i}}-\mathbf{c}\right]^{\prime}
$$

$Q_{a c f}$ distributes $\chi^{2}$ with eight degrees of freedom. In the data, only the first two autocorrelation coefficients of output growth are significant, so testing whether the endogenous-business-cycle model can explain those might seem more natural. However, the theoretical model predicts non-zero autocorrelation coefficients for many more lags than two. To capture whether the model predicts

\footnotetext{
${ }^{13}$ The test does, however, not take into account the sampling error of the empirical autocorrelation function.
} 
sufficient autocorrelation at lags of up to two quarters and not too much autocorrelation at longer lags, I included eight lags in my formal test.

Figure 2 shows the test statistic $Q_{a c f}$ as a function of the volatility of belief shocks relative to total volatility, $\frac{\sigma_{b}^{2}}{\sigma_{b}^{2}+\sigma_{z}^{2}}$, for different assumptions about the correlation between the belief and the technology shock, $\rho_{b z}$. The horizontal axis measures $\frac{\sigma_{b}^{2}}{\sigma_{b}^{2}+\sigma_{z}^{2}}$, which takes values between zero and one. For example, a value of zero represents the case that the only source of uncertainty is technology shocks, and a value of one represents the case that the only source of uncertainty is belief shocks. I computed $Q_{a c f}$ for nine different values of $\rho_{b z}$ in the interval [-1,1]. When the belief innovation is the only source of uncertainty, that is, $\sigma_{b}^{2} /\left(\sigma_{b}^{2}+\sigma_{z}^{2}\right)=1, Q_{a c f}$ is equal to 19.2. The associated probability value is .014; therefore, the null hypothesis that the difference in the first eight lags of the autocorrelation function of simulated and actual output growth can be explained by sampling error in the simulated output growth series can be rejected at the 5 percent level. When a second source of uncertainty in the form of innovations to the growth rate to technology is introduced, the model fails the $\mathrm{Q}_{a c f}$ test for all values of $\sigma_{b}^{2} /\left(\sigma_{b}^{2}+\sigma_{z}^{2}\right)$ and $\rho_{b z}$ at the 5 percent significance level. Therefore, I conclude that the model fails to explain the autocorrelation function of output growth at conventional significance levels regardless of the specific calibration of the covariance matrix governing the joint distribution of the technology and the belief shock.

\subsection{The propagation of temporary and permanent disturbances}

Another weakness of the standard real-business-cycle model is that it cannot account for the empirical regularity that the impulse response of output and hours to demand shocks is hump-shaped (Cogley and Nason, 1995). It is often claimed that business-cycle models that allow for expectationsdriven fluctuations have a richer propagation mechanism (see for example Benhabib and Farmer, 1997), and that they, therefore, might be able to account for this empirical regularity better. The results of this section suggest, however, that the model analyzed in this paper fails to account for the hump-shaped response of output and hours to a demand shock. In addition, the model fails to match the observed response of output and hours to a permanent technology shock as well.

The economy is assumed to be subject to two types of disturbance: a fundamental disturbance and a nonfundamental disturbance. The fundamental disturbance, $\sigma_{z} \epsilon_{t}^{z}$, is modeled as an innovation to the growth rate of technology, so that a positive innovation permanently increases the level of technology. The nonfundamental disturbance is modeled as revisions in agents' expectations about the future path of the economy. I allow for the possibility that revisions in expectations are correlated with technology shocks and refer to the component of the nonfundamental disturbance that is orthogonal to the technology shock as a demand shock and denote it by $\sigma_{d} \epsilon_{t}^{d}$. I wish to compare the moving average representation (in terms of $\epsilon_{t}^{d}$ and $\epsilon_{t}^{z}$ ) of per capita output growth and the level of per capita hours implied by the model to the one estimated from postwar U.S. data.

To identify the structural disturbances $\epsilon_{t}^{d}$ and $\epsilon_{t}^{z}$ in time series data, I exploit the fact that the model economy implies that the long-run effect of innovations in $\epsilon_{t}^{d}$ on the level of output 
is zero, which allows me to use the long-run identification strategy suggested by Blanchard and Quah (1989). Specifically, I estimate a three-lag vector autoregression in the rate of growth of real per capita output and the logarithm of detrended per capita hours using observations from the first quarter of 1949 to the second quarter of 1997. ${ }^{14}$ The lag-length of the vector autoregression is determined using a likelihood-ratio test. Per capita hours have a small positive deterministic trend. Since per capita hours are assumed to be stationary in the model and in the vector autoregression, the per capita hours series was detrended.

To find the moving average representation of output growth and per capita hours in terms of $\epsilon_{t}^{d}$ and $\epsilon_{t}^{z}$ predicted by the theoretical model, I simulate 1,000 time series with 194 observations each, the same number of observations as in my data set, and apply exactly the same procedure I applied to the actual time series to each simulated time series. That is, I estimate a vector autoregression of output growth and hours that includes three lags of the left hand side variables. ${ }^{15}$ Finally, I average the 1,000 estimated moving average representations.

To simulate time series from the model, I calibrate it as described in section 2.1. In addition, values must be assigned to the variance of the innovation in technology, $\sigma_{z}^{2}$, the variance of belief shocks, $\sigma_{b}^{2}$, and the correlation between technology and belief shocks, $\rho_{b z}$. I set the standard deviation of the technology shock equal to .0054, which is the estimated standard deviation of the innovation in the permanent component of output from the vector autoregression using actual data. The two remaining free parameters describing the stochastic process for the belief and technology shock, $\sigma_{b}$ and $\rho_{b z}$, are (as in section 3.1) set such that the standard deviations of consumption and hours growth relative to output growth predicted by the model are equal to those observed.

The parameters $\sigma_{b}, \sigma_{z}$, and $\rho_{b z}$ can be interpreted as follows. Under the assumption that the economy is subject to technology and belief shocks, the system of equilibrium conditions can be expressed as a bivariate stochastic vector difference equation in the (transformed) marginal utility of income and the (transformed) capital stock

$$
\hat{\mathbf{x}}_{t}=\mathbf{P} \hat{\mathbf{x}}_{t-1}+\mathbf{R} \epsilon_{\mathbf{t}}
$$

where $\hat{\mathbf{x}}_{t}=\left[\begin{array}{ll}\hat{\lambda}_{t} & \hat{k}_{t}\end{array}\right]^{\prime}$ is the vector of state variables, $\mathbf{P}$ is a $2 \times 2$ matrix whose eigenvalues all lie inside the unit circle, and $\epsilon_{t} \equiv\left[\begin{array}{ll}\epsilon_{t}^{d} & \epsilon_{t}^{z}\end{array}\right]^{\prime}$ denotes the vector of structural disturbances with $\operatorname{var}\left(\epsilon_{t}\right)=\mathbf{I}$. The elements of $\mathbf{R}$ determine the covariance matrix of the technology and belief shocks. Because the capital stock is predetermined, the (transformed) capital stock cannot be affected by demand shocks - that is, the matrix $\mathbf{R}$ is lower triangular. The element $-\mathbf{R}(2,2)$ is equal to the standard deviation of the technology shock, $\sigma_{z}$, and the two other elements can be expressed in terms of the standard deviation of belief shocks, $\sigma_{b}$, and the correlation between the technology and belief shocks, $\rho_{b z}$. If $\rho_{b z}$ is negative, then a positive technology shock, $\epsilon_{t}^{z}>0$, raises the (transformed) marginal

\footnotetext{
${ }^{14}$ Hours are measured as all private sector hours worked by wage and salary workers on nonfarm payrolls. This seasonally adjusted series is taken from the Bureau of Labor Statistics' Employment and Earnings Book (table B-10). The hours series is monthly and has been converted to quarterly averages.

${ }^{15}$ To treat actual and simulated data symmetrically, the lag-length is chosen to match the one used in the estimation of the actual vector autoregression. Alternatively, the lag-length could be determined using a likelihood-ratio test.
} 
utility of income, and from the household's first order conditions it follows that the (transformed level) of consumption falls, - that is, the level of consumption increases by less than the level of technology. The effect of a positive demand shock on the (transformed) marginal utility of income is given by $\mathbf{R}(1,1)$. I assume that, as a result of a positive demand shock, the marginal utility of income is higher than expected in the previous period, which leads to higher-than-expected equilibrium output through the effect of this change in the marginal utility of income on labor supply. The effect of an extrinsic demand shock is thus similar to the effect of an intrinsic demand shock such as a government purchases shock. Like a sunspot shock, a government purchases shock has a negative income effect and increases equilibrium output through a positive labor supply response.

The top panels of figure 3 show with solid lines the impulse response of the logarithms of output and hours to a unit demand innovation estimated from postwar U.S. data. Both output and hours increase on impact, and both responses are hump-shaped. The output response peaks after two quarters, and the hours response peaks after four quarters; then both responses revert to their respective steady-state values. The effect of the demand shock on output is over after three years, and the effect on hours is over after four years. The impulse response function of output and hours predicted by the theoretical model is shown with a dashed line. Clearly, the model fails to replicate the magnitude of the response of output and hours to a one-standard-deviation demand shock. The model predicts an initial increase in output of .0009 , whereas the estimated response is almost ten times as large at .0087. Similarly, the predicted hours response in the first period is .0021, whereas the estimated response is .0064. The predicted impulse response functions are slightly hump-shaped.

The bottom panels of figure 3 show with a solid line the estimated impulse responses of output and hours to a positive technology shock. Output is estimated to increase on impact and for several quarters thereafter. The peak response of output takes place after two years, and then output declines slowly toward its new permanently higher level. The effect on output is over after three years. The model correctly predicts a positive initial response of output that peaks after about two years, and then declines toward its new permanently higher steady-state level. However, the model predicts incorrectly that the initial response of output exceeds its long-run response. Moreover, the predicted peak response is twice as high as the long-run response, whereas the peak response in the data is only 25 percent higher than the long-run response. The discrepancy between the predicted and the observed response to a technology shock is even larger in the case of hours. In the data, positive technology shocks are, at least initially, associated with declines in aggregate hours. ${ }^{16}$ In contrast, the model predicts that hours increase on impact. The peak of the predicted increase in hours is more than five times as large as the estimated one.

One potential criticism against the way the theoretical impulse responses shown in figure 3 were constructed is that it incorrectly assumes that output growth and the logarithm of hours have a

\footnotetext{
${ }^{16}$ Blanchard and Quah (1989) use the unemployment rate rather than total hours. Consistent with my finding of an initial decline in total hours in response to a supply shock, they find that the unemployment rate first rises and only later falls below its steady-state level.
} 
third-order autoregressive representation. In fact, one can show that the theoretical model implies an ARMA(1,1) representation (see appendix B). This raises the question of whether one can adequately approximate the moving-average representation of the model by inverting a three-lag autoregressive representation. To explore whether the reported discrepancy between model and data responses is spurious - that is, whether it arises only because the inverted three-lag autoregression is a poor approximation of the moving-average process - I also compute the population impulse response functions. Figure 4 shows with a dotted line the population impulse response implied by the model and with a solid line the response estimated from actual data (repeated from figure 3). The figure reveals that the discrepancy between actual and predicted population impulse responses is even greater than the discrepancy between actual impulse responses and predicted model impulse responses when the model impulse responses are constructed from simulated time series data. As shown in the top panels, the response of neither output nor hours to a demand shock is hump-shaped. Further, the predicted population response to a technology shock is much larger and lasts much longer than that observed in U.S. data.

The magnitude of the initial response of output and hours to a demand shock depends on the size of the variance of the sunspot shock. For example, under the following alternative calibration strategy the model predicts about the same initial response of hours to a demand shock as observed in the data. Suppose the variance of the sunspot shock and its correlation with the technology shock are set such that the unconditional variance of output growth and the logarithm of per capita hours predicted by the model are equal to those observed in my sample, $.0108^{2}$ and $.0345^{2}$ respectively. ${ }^{17}$ However, under this calibration the model does not predict a hump-shaped output or hours response to demand shocks regardless of whether the model response was computed with the BlanchardQuah technique or was identified with as the population impulse response. Moreover, one can show that the model predictions are robust to variations in $\rho_{b z}, \sigma_{z}$, and $\sigma_{b}$. Therefore, I conclude that the endogenous-business-cycle model studied in this paper fails to explain the impulse response functions of output and hours to permanent and temporary disturbances.

\subsection{Forecastable movements in output, hours, and consumption}

Rotemberg and Woodford (1996) argue that forecastable movements in macroeconomic aggregates constitute the essence of business-cycle fluctuations and show that standard real-business-cycle models are unable to account for the observed comovements of forecastable changes in output, hours, consumption, and investment. Specifically, in U.S. data, forecastable changes in hours, consumption, and investment are positively correlated with forecastable changes in output whereas real-business-cycle models driven solely by random shocks to the growth rate of technology imply that hours and consumption should be expected to move in opposite directions. Rotemberg and Woodford identify this counterfactual prediction of the real-business-cycle model as its most fundamental failing. A further shortcoming of standard real-business-cycle models is that they can explain less than 10 percent of the standard deviation of forecastable changes in output when cali-

\footnotetext{
${ }^{17}$ The resulting value for $\frac{\sigma_{b}}{\sigma_{z}}$ is .75 and that for $\rho_{b z}$ is -.7 .
} 
brated so as to explain a substantial portion of the standard deviation of actual quarterly changes in output (Rotemberg and Woodford, 1996). That is, real-business-cycle models imply that the volatility of forecastable changes in output relative to actual changes in output is significantly smaller than empirical estimates of this ratio. I will address first whether an endogenous-businesscycle model - that is, a model purely driven by revisions in expectations-provides a plausible account of the observed volatility of forecastable output changes relative to actual output changes. Second, I study the model's predictions regarding comovements of forecastable changes in output, hours, consumption, and investment in the case that business cycles are due either to revisions in expectations alone or to revisions in expectations in combination with stochastic technological growth.

Table 5: Estimated and Predicted Standard Deviations of Cumulative Changes in Output

\begin{tabular}{lcccccccc}
\hline \hline & \multicolumn{7}{c}{ Horizon (in quarters) } \\
\cline { 2 - 8 } & 1 & 2 & 4 & 8 & 12 & 24 & $\infty$ \\
\hline Estimated standard deviation of & & & & & & & \\
$\widehat{\Delta y_{t}^{k}}$ & .0061 & .0105 & .0186 & .0295 & .0322 & .0305 & .0306 \\
$\Delta y_{t}^{k}$ & .0107 & .0175 & .0274 & .0379 & .0449 & .0549 & \\
Predicted standard deviation of & & & & & & & \\
$\widehat{\Delta y_{t}^{k}}$ & .0053 & .0105 & .0200 & .0328 & .0351 & .0160 & .0224 \\
$\Delta y_{t}^{k}$ & .0107 & .0164 & .0255 & .0367 & .0395 & .0265 & \\
\hline
\end{tabular}

Note. $\Delta y_{t}^{k}$ denotes the change in the log of output from $t$ to $t+k$, while $\widehat{\Delta y_{t}^{k}}$ denotes the expectation of this change based on information available at $t$. The estimated standard deviations are reproduced from Rotemberg and Woodford (1996).

Table 5 shows estimated and predicted standard deviations of expected and actual $k$-quarter changes in output. The empirical estimates of these standard deviations are derived from a vector autoregression of output growth, the consumption to output ratio, and hours and are reproduced from table 2 of Rotemberg and Woodford (1996). The predicted standard deviations are computed using the baseline calibration of the model described in section 2.1. The variance of the sunspot innovation is chosen so that the predicted variance of actual one-quarter output changes matches its empirical counterpart. ${ }^{18}$ Comparing the first and third rows of the table shows that the endogenousbusiness-cycle model predicts about the same variability in the forecastable component of output that is present in the data. Beveridge and Nelson (1981) define the cyclical component of a time series as the difference between the current value of the series and the value it is expected to have in the infinite future (net of trend). Thus, the last entries of the first and third rows of the table display the estimated and predicted standard deviation of the cyclical component of output. The endogenous-business-cycle model explains about 75 percent of the standard deviation of the cyclical component of output. The endogenous-business-cycle model also correctly predicts the relative variability of forecasted and actual output changes. At the 12-quarter horizon, the

\footnotetext{
${ }^{18}$ The resulting value of $\sigma_{b}$ is .0029 .
} 
predicted standard deviation of forecastable changes is about .9 that of actual changes, which is only slightly higher than the empirical estimate of .7. Comparing these results with those of Rotemberg and Woodford, it follows that the endogenous-business-cycle model can explain the variability in forecastable changes in output better than a real-business-cycle model can. ${ }^{19}$

Table 6: Estimated and Predicted Correlations among Forecasted Changes

\begin{tabular}{lrrrrrrr}
\hline \hline & \multicolumn{7}{c}{ Horizon (in quarters) } \\
\cline { 2 - 8 } & 1 & 2 & 4 & 8 & 12 & 24 & $\infty$ \\
\hline Estimated correlations & & & & & & & \\
$\operatorname{Corr}\left(\widehat{\Delta c_{t}^{k}}, \widehat{\Delta y_{t}^{k}}\right)$ & .69 & .78 & .82 & .82 & .79 & .72 & .68 \\
$\operatorname{Corr}\left(\widehat{\Delta h_{t}^{k}}, \widehat{\Delta y_{t}^{k}}\right)$ & .88 & .89 & .92 & .97 & .98 & .98 & .98 \\
$\operatorname{Corr}\left(\widehat{\Delta i_{t}^{k}}, \widehat{\Delta y_{t}^{k}}\right)$ & .98 & .98 & .98 & .97 & .96 & .89 & .82 \\
Predicted correlations & & & & & & & \\
$\operatorname{Corr}\left(\widehat{\Delta c_{t}^{k}}, \widehat{\Delta y_{t}^{k}}\right)$ & -.86 & -.86 & -.87 & -.85 & -.81 & -.77 & -.80 \\
$\operatorname{Corr}\left(\widehat{\Delta h_{t}^{k}}, \widehat{\Delta y_{t}^{k}}\right)$ & .98 & .98 & .98 & .98 & .98 & .98 & .98 \\
$\operatorname{Corr}\left(\widehat{\Delta i_{t}^{k}}, \widehat{\Delta y_{t}^{k}}\right)$ & .99 & .99 & .99 & .99 & .99 & .98 & .99 \\
\hline
\end{tabular}

Note. $\widehat{\Delta x_{t}^{k}}$ denotes the expected change in $x$ from $t$ to $t+k$ based on information available at $t$. The estimated correlations are taken from table 3 in Rotemberg and Woodford (1996).

I now address the question of whether the endogenous-business-cycle model can overcome Rotemberg and Woodford's main criticism of the real-business-cycle model with stochastic productivity growth - namely, that it implies counterfactual comovements between forecastable changes in hours and consumption. Following their methodology, I measure the comovement between output and other variables by the correlation of their expected $k$-quarter changes. Table 6 presents estimates and model predictions for the correlation between expected $k$-quarter changes in output and corresponding $k$-quarter changes in consumption, hours, and investment. The model predictions are computed assuming that the only source of uncertainty is revisions in expectations. The top panel of the table shows that in postwar U.S. data, expected changes in output are highly positively correlated with expected changes in consumption, hours, and investment for all forecasting horizons considered. In the case of expected hours and investment changes, the estimated correlation exceeds .9 for most forecasting horizons. Expected changes in consumption are less correlated with expected changes in output than are expected hours and investment changes.

The endogenous-business-cycle model correctly predicts the high positive correlation between expected output changes and expected hours as well as expected investment changes. However, like the real-business-cycle model, the endogenous-business-cycle model cannot replicate the empirical

\footnotetext{
${ }^{19}$ The fact that the model exactly matches the overall variance of 1-quarter changes in output is no coincidence. The volatility of the sunspot innovation is chosen so as to match this moment. Note, however, that this calibration strategy does not affect the ratio of the volatility of forecasted to actual output changes since this ratio is independent of $\sigma_{b}$.
} 
fact that forecastable changes in consumption are positively correlated with forecastable changes in hours: the model predicts a negative correlation between expected output and expected consumption changes. In a real-business-cycle model in which preference parameters and factor shares take the same values as assumed here and the only disturbances are innovations to the growth rate of technology, the correlation between forecastable changes in output and hours or investment is equal to one, and the correlation between forecastable changes in output and consumption is equal to minus one. These correlations take either the value +1 or -1 because, in that model, all variables can be expressed as a function of the (transformed) capital stock only. In the endogenous-businesscycle model, the correlation coefficient can take values other than +1 or -1 because the fact that expectations about the future path of the economy play an independent role introduces a second state variable.

Table 7: Predicted Correlations among Forecasted Changes in the Presence of Revisions in Expectations and Stochastic Technological Growth

\begin{tabular}{lrrrrrrr}
\hline \hline & \multicolumn{7}{c}{ Horizon (in quarters) } \\
\cline { 2 - 8 } & 1 & 2 & 4 & 8 & 12 & 24 & $\infty$ \\
\hline Predicted correlations & & & & & & & \\
$\operatorname{Corr}\left(\widehat{\Delta c_{t}^{k}}, \widehat{\Delta y_{t}^{k}}\right)$ & -.76 & -.74 & -.73 & -.77 & -.82 & -.85 & -.83 \\
$\operatorname{Corr}\left(\widehat{\Delta h_{t}^{k}}, \widehat{\Delta y_{t}^{k}}\right)$ & .97 & .97 & .97 & .97 & .97 & .98 & .98 \\
$\operatorname{Corr}\left(\widehat{\Delta i_{t}^{k}}, \widehat{\Delta y_{t}^{k}}\right)$ & .98 & .98 & .98 & .98 & .98 & .99 & .98 \\
\hline
\end{tabular}

Note. $\widehat{\Delta x_{t}^{k}}$ denotes the expected change in $x$ from $t$ to $t+k$ based on information available at $t$.

One interpretation of the counterfactual prediction regarding the comovement between expected consumption and output changes is that business cycles are not exclusively caused by revisions in expectation. In what follows, I allow for intrinsic uncertainty in the form of permanent disturbances to the level of technology. ${ }^{20}$ From section 3.3, we know that the propagation of a technology shock in an endogenous-business-cycle model is quite different from its propagation in a real-business-cycle model. So that the model's predictions regarding the comovement between forecastable changes in consumption and forecastable changes in output need not be the same as in the real-businesscycle model. However, table 7 shows that allowing for stochastic technical progress in addition to sunspot shocks hardly alters the predicted comovements of forecastable changes. ${ }^{21}$ In particular, the prediction of a negative correlation between forecastable consumption and output changes remains. Moreover, this comovement problem is robust to variations in the parameters $\sigma_{z}, \sigma_{b}$, and $\rho_{b z}$. Therefore, the introduction of additional disturbances in the form of permanent technology shocks does not solve the comovement problem regardless of the relative importance of technology shocks or their correlation with sunspot shocks.

\footnotetext{
${ }^{20}$ The results of section 3.1 demonstrated that additional sources of disturbances are necessary to account for the unconditional correlation between one-quarter changes in consumption and output.

${ }^{21}$ In table $7, \sigma_{z}, \sigma_{b}$ and $\rho_{b z}$ are assumed to take their baseline values, that is, $\sigma_{z}=.0054, \sigma_{b}^{2}=.21 \sigma_{z}^{2}$, and $\rho_{b z}=-.965$.
} 


\section{Countercyclical markups and procyclical consumption}

The results of section 3.1 show that in the absence of intrinsic uncertainty the endogenous-businesscycle model fails to predict procyclical consumption growth. In this section, I extend the endogenousbusiness-cycle model to allow for countercyclical markup variations as in Galí (1994). I consider this extension because it has the potential to explain positive comovements between real wages and hours worked and hence between consumption and hours in the absence of intrinsic uncertainty. A countercyclical markup acts like a positive productivity shock in the sense that it shifts the labor demand schedule out, and therefore it becomes possible that hours and real wages move in the same direction in response to a sunspot shock. By contrast, in the model studied thus far the labor demand schedule is fixed at least in the short run and so cannot explain a positive comovement between real wages and equilibrium hours (in the absence of fundamental shocks). If consumption is a normal good, the baseline model implies that hours and consumption move in opposite directions, resulting in a negative comovement between consumption and output.

The formal development of the countercyclical markup model is presented in appendix C. As in the baseline model there are two final goods, consumption and investment, and the production of the investment good is subject to sector-specific external returns to scale. However, final goods are now assumed to be produced from intermediate inputs, and producers of these intermediate inputs have market power which allows them to charge prices above marginal cost. The markup of prices over marginal cost depends on the composition of aggregate demand - in particular, under certain assumptions the model implies that the equilibrium markup is decreasing in the investment share. The main difference between Galís original model and the one developed in appendix $\mathrm{C}$ is the assumption that the production of investment goods is subject to sector-specific external returns to scale. As a consequence of this assumption, endogenous fluctuations arise for much lower average markups in this model than in Galí (1994).

To compute the quantitative predictions of the countercyclical markup model two additional steady-state parameters have to be calibrated: the steady-state markup, $\mu$, and elasticity of the markup with respect to the investment share, $\epsilon_{\mu}$. One can show that in this model the steady-state markup is equal to the degree of internal returns to scale, and I will use this restriction to calibrate the markup. Based on the empirical evidence of Basu and Fernald (1997) on internal returns to scale at the two-digit manufacturing industry level, I assign a value of .1 to returns to scale at the intermediate-goods-producing firms, that is, $\mu=1.1$. Given this value for the steady-state markup and values for the other parameters described in section 2.1, the rational expectations equilibrium is indeterminate for values of the elasticity of the markup with respect to the investment share between -.05 and .02. Since I am interested in the predictions of the model in the case that both the investment share and the markup are countercyclical, I assign a negative value to $\epsilon_{\mu}$; in particular, I set $\epsilon_{\mu}=-.04 .^{22}$ The baseline model described in section 2 is a special case of the

\footnotetext{
${ }^{22}$ It is worth mentioning that given $\mu=1.1, \theta^{I}=.1$, and $\epsilon_{\mu}<0$, indeterminacy of the perfect-foresight equilibrium no longer requires that the labor supply is perfectly elastic. For a (Frisch) labor supply elasticity of four, equilibrium is indeterminate. However, a high intertemporal elasticity of substitution is still necessary, that is, $\sigma \leq 1$ is still a
} 
countercyclical markup model in the case that $\mu=1$ and $\epsilon_{\mu}=0$.

Table 8: Countercyclical Markup Model without Intrinsic Uncertainty

\begin{tabular}{lccc}
\hline \hline & $\Delta c_{t}$ & $\Delta h_{t}$ & $\Delta i_{t}$ \\
\hline Std. dev. relative to $\Delta y_{t}$ & 0.33 & 1.27 & 4.64 \\
Autocorrelation & 0.58 & 0.33 & 0.34 \\
Cross-correlation with & & & \\
$\Delta y_{t-1}$ & 0.06 & 0.30 & 0.33 \\
$\Delta y_{t}$ & -0.55 & 0.97 & 0.98 \\
$\Delta y_{t+1}$ & -0.17 & 0.37 & 0.37 \\
\hline
\end{tabular}

Note. $\Delta x_{t}$ denotes the change in the logarithm of $X$ from $t-1$ to $t$.

The countercyclical markup model can potentially explain procyclical consumption growth in the absence of fundamental shocks. The question thus becomes whether it does so for reasonable calibrations of the model. Table 8 presents the quantitative predictions of the model and shows that consumption growth is negatively correlated with output growth. The model predicts that the contemporaneous correlation between consumption and output growth is -.55 . Recall that in the baseline endogenous-business-cycle model the correlation between consumption and output growth is -.95 . So it is true that consumption growth is less negatively correlated with output growth in the countercyclical markup model; however, this effect is quantitatively too small to imply procyclical consumption growth. One reason the model still predicts countercyclical consumption growth is that the elasticity of the markup is rather small. If one is willing to assume that steadystate markups are twice as large - that is, $\mu=1.2$ - then endogenous fluctuations occur for larger markup elasticities. Specifically, equilibrium is indeterminate for values of $\epsilon_{\mu}$ between -.08 and .03. For an elasticity of -.08 , the model predicts that the correlation between consumption and output growth is positive (.16). This calibration is problematic, however, not only because steady-state markups of 20 percent are larger than what seems empirically plausible but also because such a calibration implies that the serial correlation of consumption growth is significantly larger than empirical estimates.

Table 9 presents the implied second moments of the countercyclical markup model in the case that the model is subject to sunspot and technology shocks. As in section 3.1, the variance/covariance matrix of these two shocks is calibrated so as to match the volatility relative to output of hours and consumption growth. The resulting values are $\sigma_{b}^{2} / \sigma_{z}^{2}=.16$ and $\rho_{b z}=-.93$. For this calibration the countercyclical markup model implies procyclical consumption growth. Comparing the predictions of the countercyclical markup model with technology shocks to the baseline model with technology shock, the former fits the data slightly better. First, consumption growth is no longer negatively correlated with leading or lagging output growth. Second, the serial correlation of hours and investment growth is slightly smaller and thus closer to the data. If one were to restrict the evaluation of the model to these fifteen second moments, one might conclude

requirement for indeterminacy. 
Table 9: Countercyclical Markup Model with belief and technology shocks

\begin{tabular}{lccc}
\hline \hline & $\Delta c_{t}$ & $\Delta h_{t}$ & $\Delta i_{t}$ \\
\hline Std. dev. relative to $\Delta y_{t}$ & 0.52 & 0.94 & 3.59 \\
Autocorrelation & 0.20 & 0.55 & 0.53 \\
Cross-correlation with & & & \\
$\Delta y_{t-1}$ & 0.01 & 0.42 & 0.43 \\
$\Delta y_{t}$ & 0.46 & 0.86 & 0.92 \\
$\Delta y_{t+1}$ & 0.00 & 0.44 & 0.44 \\
\hline Note. $\Delta x_{t}$ denotes the change in the logarithm \\
of $X$ from $t$ - 1 to $t$.
\end{tabular}

that the endogenous-business-cycle model with countercyclical markups fits postwar U.S. data reasonably well. However, one can show that this endogenous-business-cycle model, like the baseline endogenous-business-cycle model, cannot account for the impulse response function of output to temporary and permanent disturbances and further cannot explain the business cycle as Rotemberg and Woodford (1996) define it.

\section{Conclusion}

This paper studies the empirical validity of the endogenous-business-cycle hypothesis as an explanation of actual fluctuations. Most existing empirical evaluations of endogenous-business-cycle models have found that their predictions are broadly consistent with the data and, in particular, not clearly less consistent with actual business cycles than the predictions of the most prominent alternative hypothesis - real business cycles. However, these studies typically test the theoretical models' predictions only about a small set of second moments, such as relative standard deviations, first-order serial correlations, and contemporaneous correlations of macroeconomic aggregates, which are aspects of aggregate fluctuations that the real-business-cycle model can capture reasonably well.

The analysis presented in this paper shows that, once the predictions of the endogenous-businesscycle model are put through the same tests that led to the rejection of real-business-cycle models as a convincing account of actual fluctuations, it becomes clear that the endogenous-businesscycle model does not fare any better. Specifically, like real-business-cycle models, the endogenousbusiness-cycle model fails to explain the auto- and cross-correlation functions of output growth, the hump-shaped response of output to Blanchard-Quah-identified demand shocks, and the comovement of forecastable changes in output and consumption. These counterfactual predictions remain after one allows for the possibility that business cycles are jointly driven by revisions in expectations and stochastic technological growth. This implication is that endogenous-business-cycle models, at least of the type analyzed in this paper, contrary to past conjectures, do not provide the propagation mechanism for technology shocks missing from real-business-cycle models. 


\section{Appendix A: Real-business-cycle model with technology and gov- ernment purchases shocks}

Table A1: Predicted comovements when the model is subject to technology disturbances

\begin{tabular}{lccc}
\hline \hline$\theta^{I}=0$ & $\Delta c_{t}$ & $\Delta h_{t}$ & $\Delta i_{t}$ \\
\hline Std. Dev. relative to $\Delta y_{t}$ & 0.47 & 0.55 & 2.33 \\
Autocorrelation & 0.10 & -0.04 & -0.03 \\
Cross-correlation with & & & \\
$\Delta y_{t-1}$ & 0.06 & -0.07 & -0.04 \\
$\Delta y_{t}$ & 0.98 & 0.98 & 1.00 \\
$\Delta y_{t+1}$ & -0.01 & 0.00 & -0.01
\end{tabular}

Note. The moments reported in table A1 are different from the corresponding moments reported in tables 1-3 due to the different assumption about the steady state share of government purchases in output, which is .177 and 0 , respectively.

Table A2: Predicted comovements when the model is subject to technology and government purchase disturbances

\begin{tabular}{lccc}
\hline \hline$\theta^{I}=0$ & $\Delta c_{t}$ & $\Delta h_{t}$ & $\Delta i_{t}$ \\
\hline Std. Dev. relative to $\Delta y_{t}$ & 0.47 & 0.60 & 2.30 \\
Autocorrelation & 0.09 & -0.04 & -0.03 \\
Cross-correlation with & & & \\
$\Delta y_{t-1}$ & 0.06 & -0.06 & -0.04 \\
$\Delta y_{t}$ & 0.92 & 0.95 & 0.99 \\
$\Delta y_{t+1}$ & -0.01 & -0.01 & -0.01 \\
\hline
\end{tabular}

Note. Following Christiano and Eichenbaum (1992) government purchases are assumed to evolve according to $\log G_{t}-\log z_{t}=$ constant $+.96\left(\log G_{t-1}-\log z_{t-1}\right)+\epsilon_{t}^{g}$, so that government purchases increase one-for-one with innovations to technology. 


\section{Appendix B}

This appendix shows that in the log-linear approximation to the solution of the model the growth rate of per capita output and the logarithm of per capita hours have an ARMA(1,1) representation.

The growth rate of per capita output, $\Delta y_{t}$, can be expressed as

$$
\begin{aligned}
\Delta y_{t} & \equiv \log Y_{t}-\log Y_{t-1} \\
& =\log \frac{Y_{t}}{z_{t}} \frac{z_{t}}{z_{t-1}} \frac{z_{t-1}}{Y_{t-1}} \\
& =\hat{y}_{t}-\hat{y}_{t-1}+\log \gamma^{z}+\sigma_{z} \epsilon_{t}^{z} \\
& =\mathbf{M Y}(\mathbf{P}-\mathbf{I}) \hat{\mathbf{x}}_{t-1}+[\mathbf{M Y}+[0-1]] \mathbf{R} \epsilon_{t}+\log \gamma^{z}
\end{aligned}
$$

where MY is a $1 \mathrm{x} 2$ vector relating $\hat{y}_{t}$ to the vector of state variables $\hat{\mathbf{x}}_{t}$. Similarly, the logarithm of per capita hours can be expressed as

$$
\begin{aligned}
h_{t} & \equiv \log H_{t} \\
& =\hat{h}_{t}+h^{*} \\
& =\mathbf{M H} \hat{\mathbf{x}}_{t}+h^{*} \\
& =\mathbf{M H P} \hat{\mathbf{x}}_{t-1}+\mathbf{M H R} \epsilon_{t}+h^{*}
\end{aligned}
$$

where $\mathbf{M H}$ is a $1 \mathrm{x} 2$ vector relating $h_{t}$ to $\hat{\mathbf{x}}_{t}$. The last equality follows from (20). Collecting terms we have

$$
\left(\begin{array}{c}
\Delta y_{t}-\log \gamma^{z} \\
h_{t}-h^{*}
\end{array}\right)=\mathbf{A} \hat{\mathbf{x}}_{t-1}+\mathbf{B} \epsilon_{t}, \text { where } \mathbf{A}=\left[\begin{array}{c}
\mathbf{M Y}(\mathbf{P}-\mathbf{I}) \\
\mathbf{M H P}
\end{array}\right] \text { and } \mathbf{B}=\left[\begin{array}{c}
{[\mathbf{M Y}+[\mathbf{0}-\mathbf{1}]] \mathbf{R}} \\
\mathbf{M H R}
\end{array}\right]
$$

Solving this equation for $\hat{\mathbf{x}}_{t-1}$ to eliminate $\hat{\mathbf{x}}_{t-1}$ from (20) yields

$$
\left(\begin{array}{c}
\Delta y_{t}-\log \gamma^{z} \\
h_{t}-h^{*}
\end{array}\right)=\mathbf{A P A}^{-\mathbf{1}}\left(\begin{array}{c}
\Delta y_{t-1}-\log \gamma^{z} \\
h_{t-1}-h^{*}
\end{array}\right)+\mathbf{B} \epsilon_{t}+\left[\mathbf{A R}-\mathbf{A P A}^{-\mathbf{1}} \mathbf{B}\right] \epsilon_{t-1},
$$

which is an $\operatorname{ARMA}(1,1)$ process.

Note that using equation (B1) the AR polynomial of output growth can be written as

$$
\Delta y_{t}-\log \gamma^{z}=\mathbf{M Y}(\mathbf{P}-\mathbf{I})(\mathbf{I}-\mathbf{P} L)^{-1} \mathbf{R} \epsilon_{\mathbf{t}-\mathbf{1}}+[\mathbf{M Y}+[0-1]] \mathbf{R} \epsilon_{\mathbf{t}} \equiv A(L) \epsilon_{\mathbf{t}}
$$

As can be easily verified $A(1)=\left[0-R_{22}\right]$, so that the long run effect of an innovation in $\epsilon_{t}^{d}$ on the level of output is zero, which is the identifying assumption I use in my empirical work. 


\section{Appendix C: An endogenous-business-cycle model with counter- cyclical markups}

There are two perfectly competitive final goods industries one producing consumption goods and the other producing investment goods. The production of the investment good is subject to external increasing returns to scale whereas returns to scale are constant in the consumption sector. Consumption and investment are produced from intermediate inputs. Specifically, the production function for the investment good is assumed to take the form

$$
I_{t}=A_{t} N^{\frac{1}{1-\eta}}\left[\sum_{i=1}^{N} x_{I}^{i} \frac{\eta-1}{\eta}\right]^{\frac{\eta}{\eta-1}} ; \quad \eta>0
$$

where $A_{t}$ denotes the external factor given by (14), $N$ the number of intermediate inputs, and $x_{I}^{i}$ the quantity of intermediate input $i$ used in the production of the investment good. Similarly, consumption is produced with a constant elasticity of substitution production function given by

$$
C_{t}=N^{\frac{1}{1-\rho}}\left[\sum_{i=1}^{N} x_{C}^{i^{\frac{\rho-1}{\rho}}}\right]^{\frac{\rho}{\rho-1}} ; \quad \rho>0
$$

where $x_{C}^{i}$ is the quantity of intermediate input $i$ allocated to the production of consumption goods. An important assumption of the model is that consumption and investment goods are produced with different elasticities of substitution: consumption goods are produced with an elasticity of substitution of $\rho>0$, and investment goods are produced with an elasticity of substitution of $\eta>0$.

Suppose a consumption good producer wants to produce $C_{t}$ units of the final good. From his cost minimization problem one finds that the demand faced by intermediate good $i$ producer, $c_{t}^{i}$, is

$$
c_{t}^{i}=\left[\frac{p_{t}^{i}}{\left[N^{-1 / \rho} \sum_{j=1}^{N} p_{t}^{j^{(1-\rho)}}\right]^{1 /(1-\rho)}}\right]^{-\rho} C_{t} .
$$

The intermediate good producer faces a similar demand from the sector producing investment goods with $I_{t} / A_{t}$ replacing $C_{t}$ in the above expression. Then the total demand for intermediate good $i, y_{t}^{i}$, is simply the sum of demands from consumption and investment goods producers, that is, $y_{t}^{i}=c_{t}^{i}+i_{t}^{i}$. I assume that intermediate goods producers cannot price-discriminate between investment and consumption demand and restrict the analysis to a symmetric equilibrium in which all intermediate good producers charge the same price $\bar{p}$.

In a symmetric equilibrium in which the number of firms is large and all other firms except firm 
$i$ charge $\bar{p}$, marginal revenue of the firm producing intermediate good $i$ can be approximated by

$$
M R_{t}^{i}\left(y^{i}\right)=p_{t}^{i}\left(y_{t}^{i}\right)\left(1-\frac{y_{t}^{i} N / Y_{t}}{\rho\left(p_{t}^{i} / \bar{p}\right)^{-\rho}\left(C_{t} / Y_{t}\right)+\eta\left(p_{t}^{i} / \bar{p}\right)^{-\eta} I_{t} /\left(A_{t} Y_{t}\right)}\right),{ }^{23}
$$

where $Y_{t}$ is the level of aggregate demand in period t measured in units of the consumption good. In a symmetric equilibrium, firm $i$ will also charge $\bar{p}=1$, so that $i_{t}^{i}=I_{t} /\left(N A_{t}\right)$ and $c_{t}^{i}=C_{t} / N$. This further implies that the price of the investment good in terms of the consumption good, $p_{t}$, is given by

$$
p_{t}=1 / A_{t}
$$

that firm level output is proportional to aggregate output, $y_{t}^{i}=Y_{t} / N$, and that by (C3) marginal revenue for any firm is

$$
M R_{t}^{i}\left(y^{i}\right)=1-\frac{1}{\rho\left(1-s_{t}\right)+\eta s_{t}},
$$

where $\left(1-s_{t}\right)$ and $s_{t}$ are the shares of, respectively, consumption and investment in aggregate demand in period $t$, that is

$$
s_{t}=\frac{p_{t} I_{t}}{Y_{t}}
$$

I assume that the elasticity of demand, $\rho\left(1-s_{t}\right)+\eta s_{t}$, is always greater than one, so that marginal revenue is positive. The elasticity of demand faced by a firm depends on the composition of aggregate demand unless the elasticity of demand for investment goods equals that of consumption goods, that is, unless $\rho=\eta$.

All intermediate goods producer have access to the same technology, which is described by

$$
y_{t}^{i}=F\left(K_{t}^{i}, z_{t} H_{t}^{i}\right)-\phi z_{t},
$$

where $K_{t}^{i}$ are the capital services rented in period $t$ by firm $i$, and $H_{t}^{i}$ is the number of hours hired by firm $i$ in period $t$. I assume that $F(.,$.$) is concave, strictly increasing in both arguments, and$ homogeneous of degree one. The last assumption implies that marginal cost are independent of scale of production. The elasticity of substitution between capital and labor is assumed to be unity. Firms have internal increasing returns due to the fixed cost $\phi z_{t}>0$.

Profit maximization of the firms producing intermediate goods requires that marginal revenue is equated to marginal cost:

$$
\frac{\rho\left(1-s_{t}\right)+\eta s_{t}-1}{\rho\left(1-s_{t}\right)+\eta s_{t}}=M C_{t}
$$

which implies that the markup of prices over marginal cost, $\mu_{t}$, satisfies

$$
\mu_{t}=\frac{\rho\left(1-s_{t}\right)+\eta s_{t}}{\rho\left(1-s_{t}\right)+\eta s_{t}-1}
$$

${ }^{23}$ The approximation is that $\left[N^{-1 / \rho} \sum_{j=1}^{N} p_{t}^{j{ }^{1-\rho}}\right]^{1 /(1-\rho)}=\bar{p} N^{-1 / \rho}$ when all firms but firm $i$ charge $\bar{p}$. 
Unless the elasticities of substitution for investment and consumption demand are equal, the markup is variable over time and depends on the share of investment in aggregate demand. Finally, labor demand is given by

$$
z_{t} F_{H}\left(K_{t}^{i}, z_{t} H_{t}^{i}\right)=\mu_{t} w_{t}
$$

and the demand for capital by

$$
F_{K}\left(K_{t}^{i}, z_{t} H_{t}^{i}\right)=\mu_{t} u_{t} .
$$

Profits of firm $i$ are given by $y_{t}^{i}-w_{t} H_{t}^{i}-u_{t} K_{t}^{i}=y_{t}^{i}-F\left(K_{t}^{i}, z_{t} H_{t}^{i}\right) / \mu_{t}$. If fixed costs $\phi z_{t}$ were zero and $\mu>1$, then firms would on average earn pure profits. This is not observed in U.S. postwar data. I require, therefore, pure profits to be zero in the steady state. This is the case if $y^{i}=\phi z_{t} /(\mu-1)$ and can be brought about through the endogenous determination of $N$. I assume that in steady state the number of firms $N$ (or the number of differentiated goods) is such that profits are zero for each firm. This assumption seems reasonable because persistent pure profits would lead to entry through the introduction of new goods and persistent losses would cause exit of firms and the number of differentiated goods would decrease.

The equilibrium conditions in terms of aggregates in a symmetric equilibrium are described next. Aggregate value added is determined by

$$
Y_{t}=N F\left(K_{t} / N, z_{t} H_{t} / N\right)-N \phi z_{t}
$$

which in equilibrium has to equal aggregate demand

$$
Y_{t}=C_{t}+p_{t} I_{t}
$$

where

$$
p_{t}=\left(I_{t} / z_{t}\right)^{\frac{-{ }^{I}}{1+\theta^{I}}}
$$

Aggregate factor demands are related to factor prices through the relations

$$
z_{t} F_{H}\left(K_{t} / N, z_{t} H_{t} / N\right)=\mu_{t} w_{t}
$$

and

$$
F_{K}\left(K_{t} / N, z_{t} H_{t} / N\right)=\mu_{t} u_{t}
$$

with the markup $\mu_{t}$ determined by (C5).

These equations describe the production side of the model with countercyclical markups. The other parts of the model are the same as in the model described in section 2. A rational expectations equilibrium is the set of stochastic processes for the endogenous variables $\left\{s_{t}, p_{t}, I_{t}, Y_{t}, \mu_{t}, K_{t}, H_{t}, w_{t}, u_{t}, C_{t}, \lambda_{t}\right\}$ satisfying (2)-(3), (17)-(18), and (C4)-(C10). When $\mu=1$ and $\phi=0$, these are the equilibrium conditions of the model described section 2 .

The model is transformed into stationary variables. It can be shown that a steady state in terms 
of the stationary variables exists. The model solution is approximated by log-linearizing around the steady state. This linearization now involves two additional free parameters that need to be calibrated, the steady-state markup, $\mu$, and elasticity of the markup with respect to the investment share, $\epsilon_{\mu} \cdot 24$

\footnotetext{
${ }^{24}$ One can show that the assumptions $\eta, \rho>0$ and $\rho\left(1-s_{t}\right)+\eta s_{t}>1$ imply that in steady state $\mu>1$ and $1-\mu<\epsilon_{\mu}<s_{I} / s_{C}(\mu-1)$ (see Schmitt-Grohé, 1997).
} 


\section{References}

Basu, Susanto, and Fernald, John G. "Are Apparent Productive Spillovers a Figment of Specification Error?" Journal of Monetary Economics 36 (August 1995): 165-88.

Basu, Susanto, and Fernald, John G. "Returns to Scale in U.S. Production: Estimates and Implications" Journal of Political Economy 105 (April 1997): 249-283.

Benhabib, Jess, and Farmer, Roger E.A. "Indeterminacy and sector-specific Externalities." Journal of Monetary Economics 37 (June 1996): 421-43.

Benhabib, Jess, and Farmer, Roger E.A. "Indeterminacy and sunspots in macroeconomics" Manuscript. October 1997, prepared for the Handbook of Macroeconomics.

Beveridge, Stephen and Nelson, Charles R. "A New Approach to the Decomposition of Economic Time Series into Permanent and Transitory Components with Particular Attention to Measurement of the 'Business Cycle"' Journal of Monetary Economics 7 (March 1981): 151-74.

Blanchard, Olivier, and Quah, Danny "The Dynamic Effects of Aggregate Demand and Supply Disturbances" American Economic Review 79 (September 1989): 655-673.

Burnside, Craig "Production Function Regressions, Returns to Scale, and Externalities" Journal of Monetary Economics 77 (April 1996): 177-201.

Burnside, Craig, Eichenbaum, Martin, and Rebelo, Sergio "Labor Hoarding and the Business Cycle" Journal of Political Economy 101 (April 1993): 245-73.

Christiano, Lawrence and Eichenbaum, Martin "Current Real-Business-Cycle Theories and Aggregate Labor-Market Fluctuations" American Economic Review 82 (June 1992): 430-50.

Cogley, Timothy, and Nason, James M. "Output Dynamics in Real-Business-Cycle Models." American Economic Review 85 (June 1995): 492-511.

Farmer, Roger E.A., and Guo, Jang-Ting "Real Business Cycles and the Animal Spirits Hypothesis" Journal of Economic Theory 63 (June 1994): 42-72.

Galí, Jordi "Monopolistic Competition, Business Cycles, and the Composition of Aggregate Demand" Journal of Economic Theory 63 (June 1994): 73-96.

Hansen, Gary D. "Indivisible Labor and the Business Cycle" Journal of Monetary Economics 16 (November 1985): 309-327.

Harrison, Sharon G. "Production Externalities and Indeterminacy in a Two Sector Model: Theory and Evidence." Manuscript. Evanston, Ill.: Northwestern University, November 1996.

King, Robert G., Plosser, Charles I., and Rebelo, Sergio T. "Production, Growth, and Business Cycles I. The Basic Neoclassical Model” Journal of Monetary Economics 21 (1988a): 195-232.

King, Robert G., Plosser, Charles I., and Rebelo, Sergio T. "Production, Growth and Business Cycles II. New Directions" Journal of Monetary Economics 21 (1988b): 309-341.

Kydland, Finn E., and Prescott, Edward C. "Time to Build and Aggregate Fluctuations" Econometrica 50 (November 1982): 1345-70.

Perli, Roberto "Indeterminacy, Home Production, and the Business Cycle: a Calibrated Analysis" Manuscript. New York, NY: New York University, April 1995. 
Rotemberg, Julio J., and Woodford, Michael. "Oligopolistic pricing and the effects of aggregate demand on economic activity" Journal of Political Economy 100 (December 1992): 1153-1207.

Rotemberg, Julio J., and Woodford, Michael. "Real-Business-Cycle Models and the Forecastable Movements in Output, Hours, and Consumption." American Economic Review 86 (March 1996): 71-89.

Schmitt-Grohé, Stephanie. "Comparing four models of aggregate fluctuations due to self-fulfilling expectations" Journal of Economic Theory 72 (January 1997): 96-147.

Weder, Mark "Animal spirits, technology shocks and the business cycle" Manuscript. Humboldt University Berlin,, 1997. 
Figure 1: Estimated and Predicted Autocorrelation Function of Output Growth

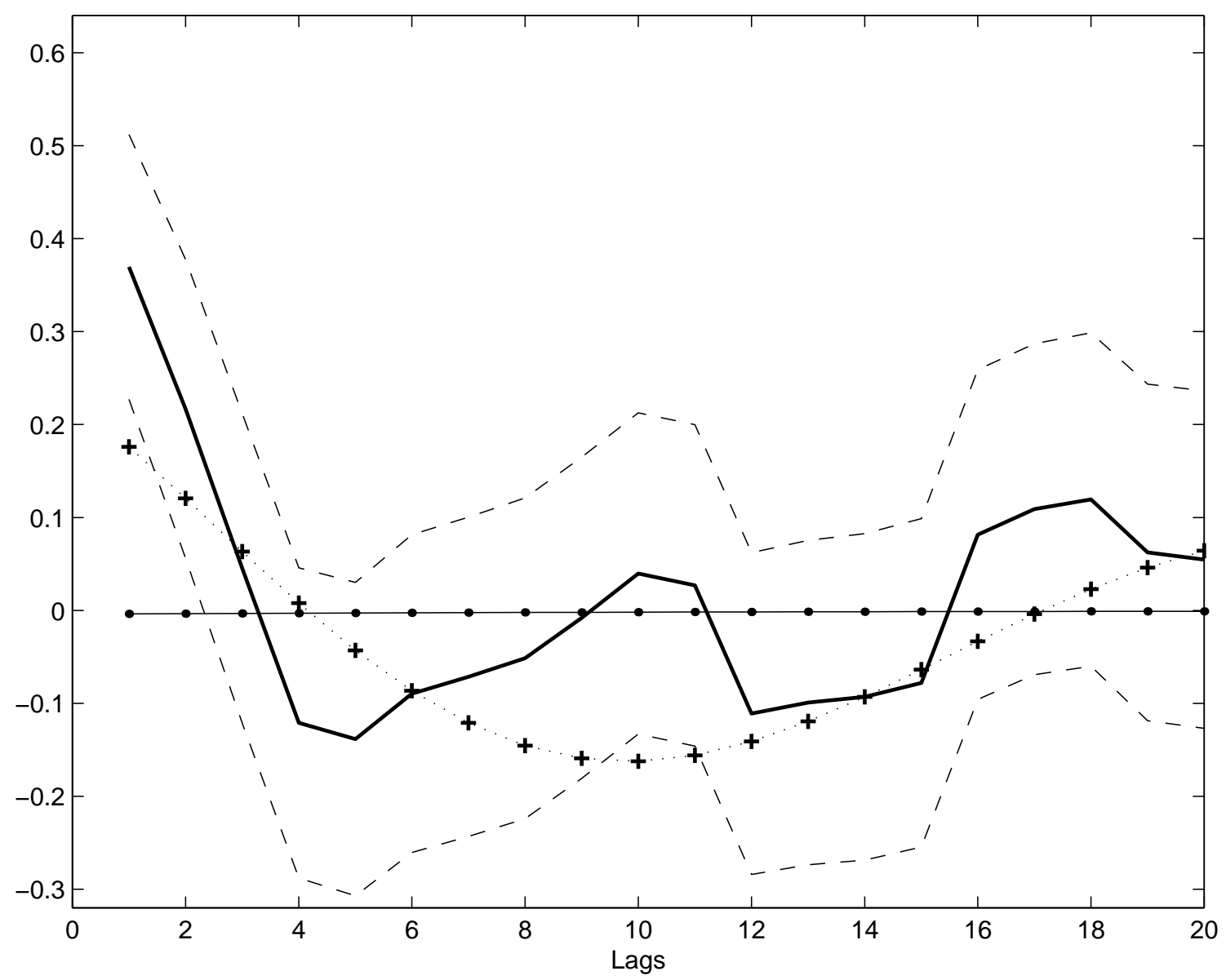

Note. The solid line shows the sample autocorrelations, the dashed lines describe a two standard error confidence band around the sample autocorrelations, the crossed line shows the autocorrelations predicted by the endogenous-business-cycle model, and the chain-dotted line shows autocorrelations predicted by a real-business-cycle model. 
Figure 2: $Q_{a c f}$ as a function $\frac{\sigma_{b}^{2}}{\sigma_{z}^{2}+\sigma_{b}^{2}}$ for nine different values of $\rho_{b z}$

Sample, 1948:2-1997:2

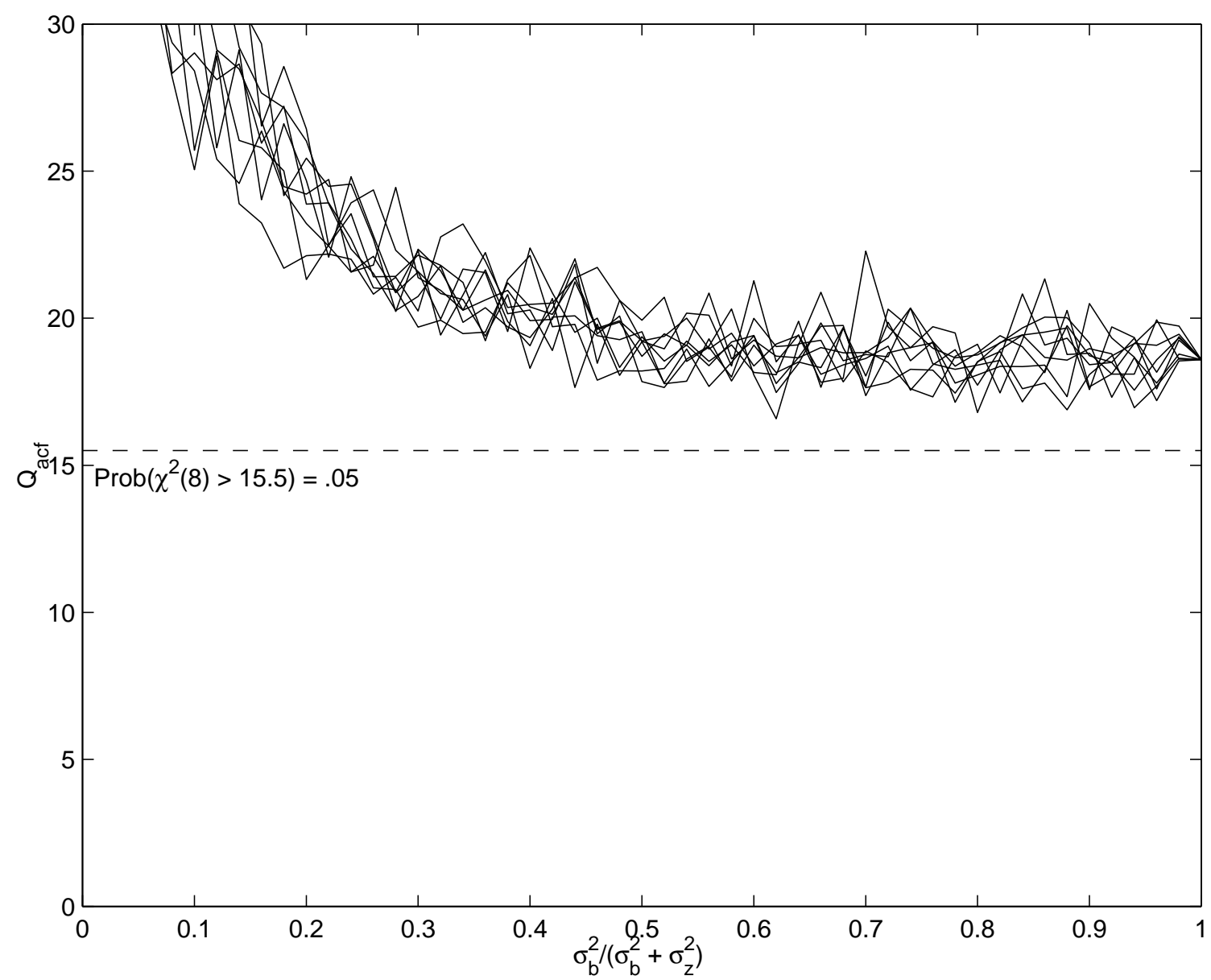

Note. Each solid line shows the test statistic for the autocorrelation function $Q_{a c f}$, defined in equation (19), as a function of $\frac{\sigma_{b}^{2}}{\sigma_{b}^{2}+\sigma_{z}^{2}}$ for a particular value of $\rho_{b z}$ between -1 and 1 . $Q_{a c f}$ follows a $\chi^{2}$ distribution with 8 degrees of freedom. The dashed lines indicates the five percent critical value. 
Figure 3: Estimated and Predicted Impulse Response Functions
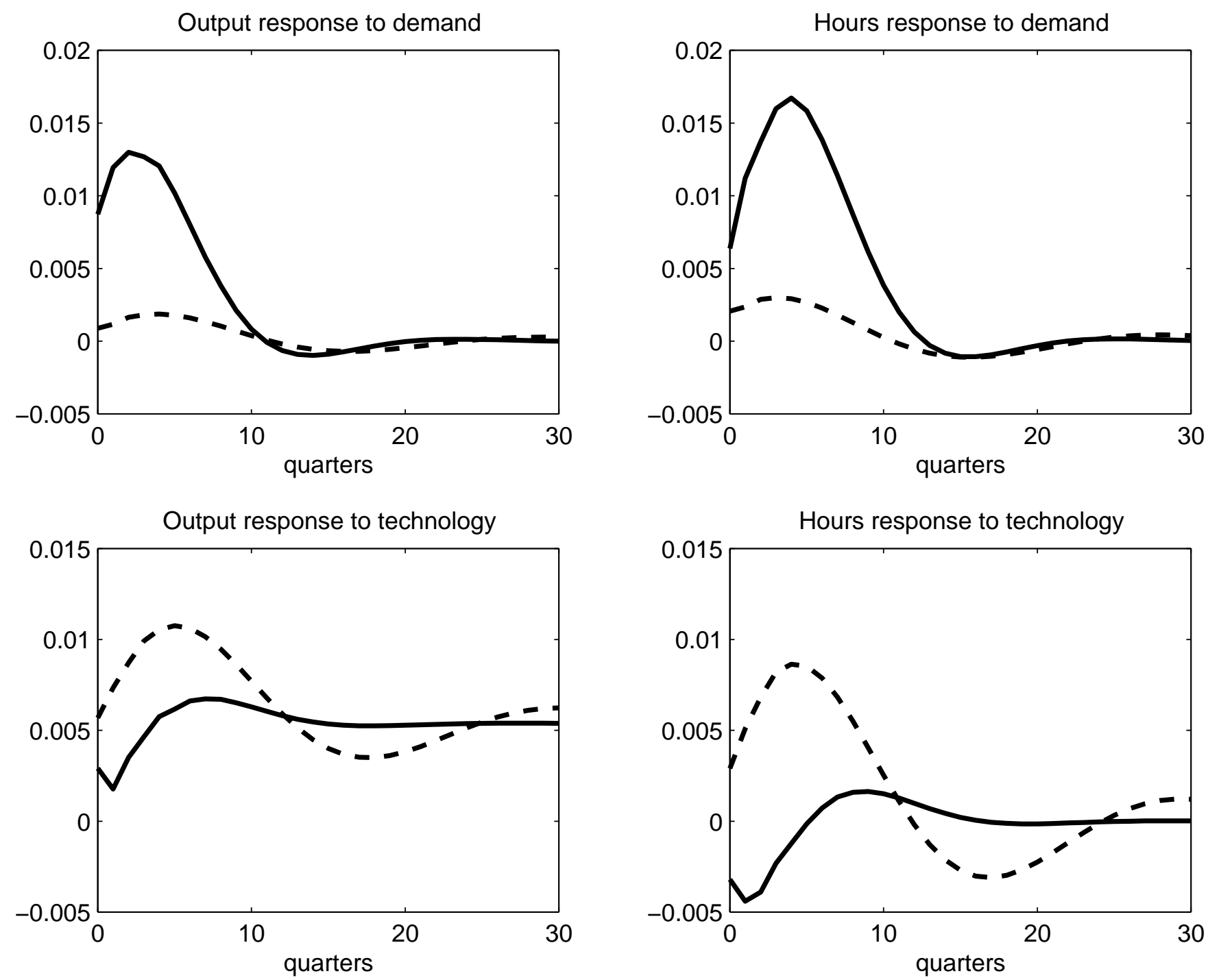

Note. The solid line shows the empirical response, and the dashed line shows the response estimated from simulated time series data generated by a calibrated version of the model. 
Figure 4: Estimated and Predicted (Population) Impulse Response Functions
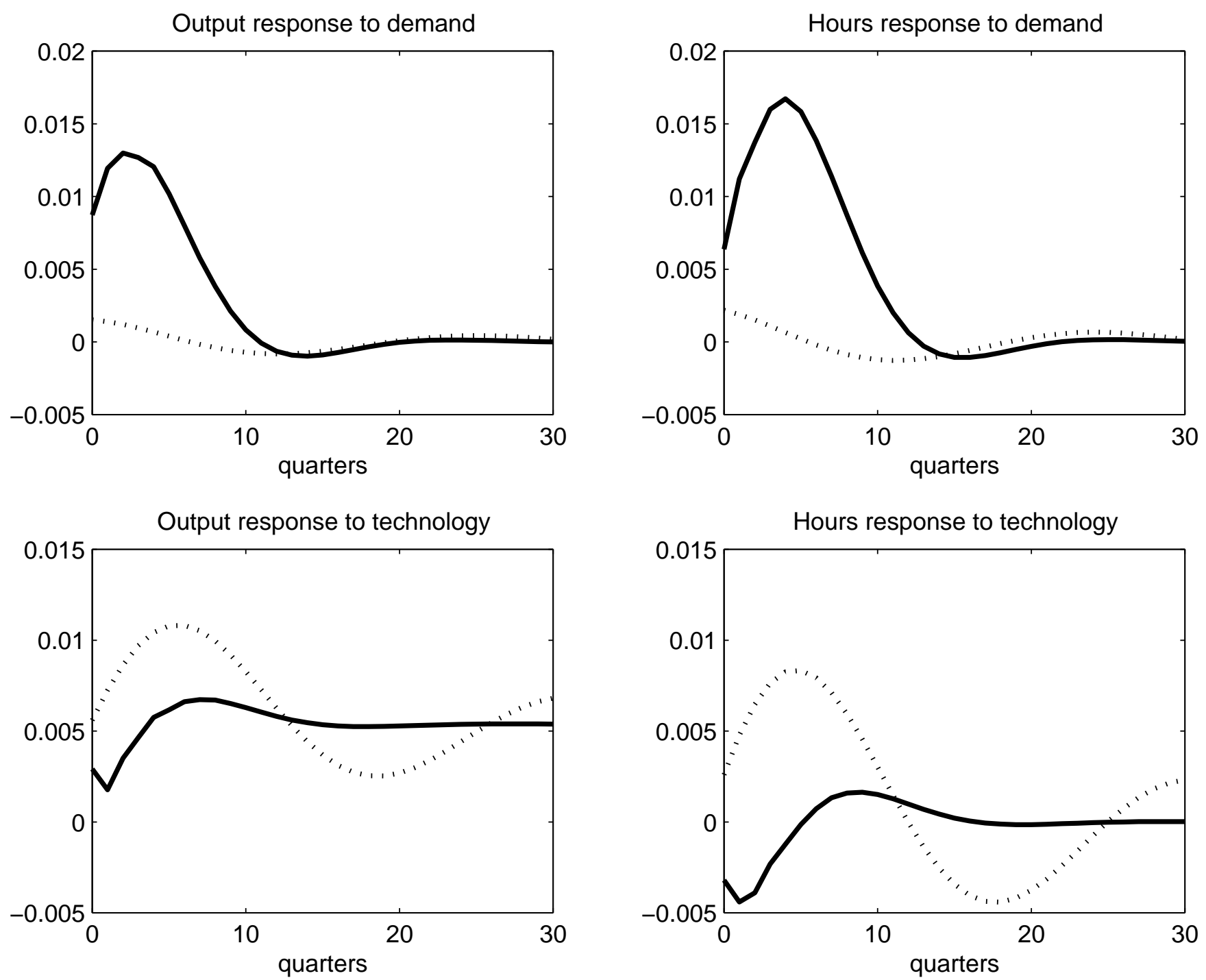

Note. The solid line shows the empirical impulse response, and the dotted line shows the population response implied by a calibrated version of the model. 